\title{
The Relationship of Curriculum, Teaching Methods, Assessment Methods, and School and Home Environment with Learning Difficulties in English Language from the Students' Perspectives
}

\section{Mohamad Ahmad Saleem Khasawneh*}

\author{
Special Education Department, King Khalid University, Saudi Arabia \\ *Correspondence to: mkhasawneh@kku.edu.sa
}

\begin{abstract}
This study aimed to identify the relationship between curriculum, teaching methods, and assessment methods, and school and home environment and learning difficulties in English language among students in the elementary stage in Irbid Governorate from the students' point of view. The study used the descriptive-analytic approach. The sample of the study consisted of (100) male and female students, who teach the fourth and fifth grades, distributed as follows: (50) males and (50) females. To achieve the objectives of the study, a questionnaire was designed to identify the relationship between curriculum, teaching methods, and assessment methods, and school and home environment and learning difficulties among students in English language. The questionnaire included the following dimensions, curriculum, teaching methods, and assessment methods, and school and home environment. The results of the study revealed that the overall degree for the relationship between curriculum, teaching methods, and assessment methods, and school and home environment to students' learning difficulties In English language at the primary stage from the students' point of view was high in all dimensions of study. The study concluded that it is important to identify the importance of curriculum, teaching methods, and assessment methods, and school and home environment for students with LDs and students should be aware of these factors and their role.
\end{abstract}

Keywords: english language; curriculum; teaching methods; assessment methods; school and home environment; learning disabilities

Recommended citation: Khasawneh, M. A. S. (2022). The Relationship of Curriculum, Teaching Methods, Assessment Methods, and School and Home Environment with Learning Difficulties in English Language from the Students' Perspectives. Journal of Innovation in Educational and Cultural Research, 3(1), 41-48.

\section{INTRODUCTION}

In recent years, English language has facilitated the widespread of the electronic network in the field of public communication. This spread in turn has contributed to improving the use of English as an international language (Almousah, 2020). In addition, Al-Arifi (2020) emphasized that English is the language of communication and understanding between many countries of the world, as it is the language of political and scientific conferences and forums, and the language of publishing and scientific research in many fields, especially technical and medical ones. Therefore, the Jordanian Ministry of Education has continuously developed the teaching of English language, as English is the second official language in Jordan.

There are clear indications of students' weakness in English language, as students are unable to speak English, and their ability to comprehend and understand written texts is also weak (Minshar, 2020). In addition, students are weak in understanding conversations they listen to in English and are weak in written expression. This led to the increase in learning disabilities in English language among students and its great impact on the future of children, their social and professional lives, and their psychological stability. Such a phenomenon requires a comprehensive, careful and insightful view of the familial, social, and economic factors interacting with the preparations, tendencies, and psychological trends of each student separately. It is also important to avoid random judgments and intolerant trends such as the misconception of some teachers and parents that learning disabilities are linked to misunderstanding and mental retardation (Musaed, 2018). Therefore, this problem triggered the researcher to investigate and identify the most important reasons behind the students' learning difficulties in English language, including those related to curriculum, teaching methods, assessment methods, school and home environment. 


\section{Problem Statement}

The level of students in the elementary stage in English language does not meet the expected learning outcomes in various language skills (Al-Zoubi, 2013). Therefore, it has become necessary to identify the causes of students' learning disabilities in English language from its various aspects. The rationale behind this reason is that English language is very important in achieving the objectives of the educational system and the progress of individuals scientifically and practically. The idea of this study came to identify the relationship between curriculum, teaching methods, assessment methods, school and home environment to the learning disabilities of students in English language and methods of treating them. Therefore, it was necessary to take the opinions of students to face these difficulties, as taking their opinions will lead to a deeper understanding of the language, in addition to achieving better performance on the part of both the teacher and the learner alike.

\section{Research Objectives}

This study aimed at achieving the following objectives: 1) Identifying the causes of learning disabilities among students in English language at the elementary stage in Irbid Governorate from the students' point of view; 2) Identifying the relationship between curriculum, teaching methods, assessment methods, school and home environment and learning difficulties in English language.

\section{Research Questions}

The present study seeks to give answers to the following research question: What is the relationship of curriculum, teaching methods, assessment methods, school and home environment with the learning disabilities of students in English language in Irbid from the students' point of view?

\section{Significance of the Study}

The significance of the current study stems from the importance of English language as the first global language that contributes to the progress of individuals scientifically and practically, so everyone needs to learn it. Therefore, research on the relationship of curriculum, teaching methods, assessment methods, school and home environment to students' learning difficulties in English language may contribute to finding solutions for these reasons. This will help reduce the number of students with learning difficulties in English language in the future. The current study also derives its significance from the importance of the elementary stage, which represents the first pillar of the next educational stage in the educational system, which depends on its quality, and development of students' academic performance (Saadeh \& Dhmour, 2017).

\section{Delimitations of the Study}

The results of this study are limited to human limitations, as it was applied to the fourth and fifth primary teachers of English. The study tools were applied in public primary schools in the Second Directorate of Education in Irbid Governorate during the second semester of the academic year 2020/2021. The results of the study also are limited to the validity and reliability of the study instrument.

\section{Definition of Operational Terms}

The primary stage: is defined as the stage at the beginning of the educational ladder, where students undertake their spiritual, physical, intellectual, emotional, and social care in a manner consistent with the nature of each student and according to the goals of the society in which they live (Al-Mutairi, 2009). The researcher defines it procedurally as the stage that includes students from the fourth grade to the sixth grade in public schools in the Second Education Directorate in Irbid Governorate.

Reasons: They are defined as the factors that stand behind a particular problem or work to make something happen (Olimat, et al, 2013).

Students with learning disabilities: those who have disorders in one or more of the basic psychological processes, which include understanding of written or spoken language and their use (Khasawneh, 2019).

Poor achievement: It means the poor performance level of students in the acquisition and learning of English language in terms of speed and degree of proficiency (Al-Sane, 2009). The researcher defines it procedurally as the weakness of achieving the educational goals that the curriculum is designed to achieve among primary school students as a result of a group of factors and influences, which negatively affect the students' school performance.

Students face difficulties in learning English as a second language, which is a multifaceted problem that requires organized and multidimensional solutions. They also face other challenges related to mastering the skills necessary for reading comprehensions, such as rapid recognition of words and an abundance of linguistic vocabulary. They need a kind of education that directly solves their deficits and promote their language level (Nuruzzaman, et al., 2018).

The problem of students' weakness in English language is one of the challenges facing researchers in the 
field of teaching and learning English in general. The improvement of students' achievement in English language confirms the good progress of the education process in the right direction. In addition, the teacher grows a positive motivation towards the teaching profession and helping students achieve better. On the other hand, we will find that the achievement of many students in English language is a complex problem, as they feel that it is an unsuitable subject for them and that whatever they do they will not be good at. Therefore, so we must look into the reasons behind the formation of negative trends towards the acquisition of English language subject, the most important of which is the low achievement rate (Turki, 2019).

The general atmosphere prevailing in elementary schools neither helps nor encourages learning English language. The student speaks Arabic with the school administration and teachers and learns Arabic language in all subjects. The remaining time to learn English is just limited to a class of forty-five minutes, most of which is covered with Arabic. The time specified to learning English language is very limited compared to other study subjects, which is of course not enough for students to practice and acquire the language. Therefore, it is necessary to take advantage of all the opportunities available to the student in learning the language. As for teaching methods, we find that they do not achieve their goal for several reasons, including that teachers do not speak English in their performance and focus on giving information and teaching it as a subject only, regardless of the purpose of teaching English. In addition, teachers focus on the written contents of the curriculum and neglect the verbal side of the language.

\section{PREVIOUS STUDIES}

Several studies have been conducted to investigate the reasons behind learning disabilities in English language and these studies have come up with different results. Yousif \& Abdallah (2020) investigated English prepositions problems encountered by Sudanese university students. To collect the data for this study, the author used a test for the participants and followed the descriptive-analytical method. The sample of this study consisted of 50 second-year English Language students from the Faculty of Arts at Al Neelain University academic year (2017-2018). SPSS was used to analyze the data. The results of the study showed that English prepositions cause great difficulty for Sudanese university students and that the interference of Arabic language is a direct cause of the problem of literal translation from Arabic into English.

Al-Arifi (2020) aimed to identify the difficulties facing teaching English Language at the primary level from the point of view of teachers and the proposed solutions for them. The sample of this study consisted of 88 female English Language teachers at the primary level in Al-Quwaiyah Governorate, where only 83 responded to the survey. This study followed the Descriptive Approach (Survey) where SPSS, Pearson correlation, Cronbach's Alpha, and Standard Deviation were used as tools to analyze the collected data. The result of this study showed that the difficulties facing English language teaching at the primary level in Al-Quwaiyah governorate include four elements: Difficulties related to the educational environment, difficulties related to the academic curriculum, difficulties related to teaching methods, and difficulties related to the teacher.

Khalaf \& Fadel (2020) aimed to analyze the written discourse errors made by Iraqi English Language students and to suggest error solutions. The sample of this study consisted of 20 essays that have been written by 3rd year English Department students at the University of Anbar. The author followed the qualitative method and used Corder's 1974 steps of error analysis. The results of this study showed that the written discourse errors are made mostly because of the difficulties of learning English as a foreign language and the interference between the Arabic language and acquired one.

Badawi \& Hamid (2020) aimed to analyze the difficulties encountered by Sudanese government school students in pronouncing some consonant sounds and clusters. The sample of this stud consisted of 20 students from Al Izba Basic School for Girls-Al-Amlak-Khartoum. This study followed the descriptive-analytical method, and to collect data from teachers the author used a questionnaire. The study followed the quantitative method and to collect the data the researcher used a questionnaire as an instrument. The findings of the study showed that some factors harm pronunciation, such as inadequate training in phonetics the differences in sound systems between Arabic and English, and phonology.

Abu Salah \& Al-Hadidi (2017) aimed to identify the difficulties of learning writing in English language faced by $(4-6)$ primary grade students from the point of view of their teachers in the capital city Amman. The sample of this study consisted of 351 randomly chosen teachers (58 males and 293 females) from the Directorate of Education / Kasbah District in the capital Amman. The study followed the descriptive survey approach. The author designed a survey that consisted of 40 paragraphs. The results of the study showed that the level of difficulties in learning to write in English language came in a high level and all areas. 


\section{METHODS}

This section provides information on the methodology of the present study, which includes population and sample, research instrument, and validity and reliability of the instrument.

\section{Population and Sample}

The sample of the study consisted of 100 students, who were selected from fourth, fifth and sixth grades. 10 schools of males and females students were chosen by the stratified random method to consist of ( 5 schools for females) and ( 5 schools for males) and the study was conducted on a sample of (100 male and female students) as shown in Table 1.

Table 1. Distribution of the study sample according to independent variables

\begin{tabular}{cccc}
\hline Variable & Category & Frequencies & Percentage (\%) \\
\hline Gender & Male & 150 & 50 \\
& Female & 150 & 50 \\
Grade & Fourth & 100 & 33.33 \\
& Fifth & 100 & 33.33 \\
& Sixth & 100 & 33.33 \\
\hline & Total & 300 & 100.0 \\
\hline
\end{tabular}

\section{Research Instrument}

The instrument of the study consisted of a measure of the relationship of curriculum, teaching methods, assessment methods, school and home environment to students' learning difficulties in English at the primary stage from the students' point of view. The study instrument consisted of two parts. Part one included general information about the study sample (students). The second part included the statements of the questionnaire addressed to teachers, which were divided into the following topics (curriculum, teaching methods, assessment methods, school and home environment). The response was graded on each statement according to a triple scale and was determined at three levels: high (3 degrees), medium (2 degrees), and low (1 degree).

\section{Validity and Reliability of the Instrument}

To ensure the validity of the instrument, the correlation coefficient was calculated. The correlation coefficients are shown in Table 2 below.

Table 2. Cronbach's alpha internal consistency coefficient and repetition stability of the instrument

\begin{tabular}{ccc}
\hline Field & Test Re-test & Internal consistency \\
\hline Curriculum & 0.87 & 0.71 \\
Teaching methods & 0.88 & 0.82 \\
assessment methods & 0.90 & 0.89 \\
School and home environment & 0.92 & 0.87 \\
Causes of weakness as a whole & 0.91 & 0.95 \\
Solutions & 0.89 & 0.90 \\
\hline
\end{tabular}

Table 2 shows that the value of the total reliability coefficient of the study instrument was (0.89), where the School and home environment field obtained the highest stability factor (0.91), and the lowest stability factor was $(0.87)$ for the speaking field.

\section{RESULT AND DISCUSSION}

This section provides the findings obtained from the present study. These findings are presented based on the research questions that guide the present research. To answer this question, the mean scores and standard deviations of the relationship of curriculum, teaching methods, assessment methods, school and home environment to students' learning difficulties in English were extracted as follows.

\section{The first field: curriculum}

Table 3 shows the mean scores and standard deviations of the relationship of language skills with learning difficulties among English language students and the overall degree of for the curriculum field. 
Table 3. The mean scores and standard deviations of the statements of the curriculum field arranged in descending order according to the mean scores

\begin{tabular}{|c|c|c|c|c|}
\hline Rank & Statement & $\begin{array}{l}\text { Mean } \\
\text { score }\end{array}$ & $\begin{array}{l}\text { Standard } \\
\text { deviation }\end{array}$ & Level \\
\hline 1 & $\begin{array}{l}\text { The curriculum does not meet the desires and tendencies of the } \\
\text { students }\end{array}$ & 2.25 & .753 & Medium \\
\hline 2 & $\begin{array}{l}\text { Curriculum attention to grammar without focusing on the use of } \\
\text { language }\end{array}$ & 2.22 & .749 & Medium \\
\hline 3 & $\begin{array}{l}\text { The density of the curriculum, which makes the teacher in a race } \\
\text { against time to cover the curriculum }\end{array}$ & 2.21 & .734 & Medium \\
\hline 4 & $\begin{array}{l}\text { Weakness of the curriculum link with the local environment of the } \\
\text { student }\end{array}$ & 2.18 & .778 & Medium \\
\hline 5 & Lack of clarity about the purposes of teaching English & 2.14 & .735 & Medium \\
\hline 6 & $\begin{array}{l}\text { The English language curriculum is not computerized for all } \\
\text { academic levels }\end{array}$ & 2.14 & .764 & Medium \\
\hline 7 & Curriculum difficulty or weakness & 2.13 & .783 & Medium \\
\hline & $\begin{array}{cc}\text { Total } \\
\end{array}$ & 2.18 & .508 & Medium \\
\hline
\end{tabular}

It is clear from the results in Table 3, that the overall degree of responses for the causes of learning difficulties was high and all of its statements were medium. the statement, "the curriculum does not meet the desires and tendencies of the students" came in the first place, while the statement, "curriculum difficulty or weakness" came in the last rank.

\section{The second field: teaching methods}

Table 4 shows the mean scores and standard deviations of the causes of students' learning difficulties in English in the primary stage, and the total degree of appreciation for the field of teaching methods and its substatements.

Table 4. The mean scores and standard deviations of the statements of the teaching methods field arranged in descending order according to the mean scores

\begin{tabular}{|c|c|c|c|c|}
\hline Rank & Statement & $\begin{array}{l}\text { Mean } \\
\text { score }\end{array}$ & $\begin{array}{l}\text { Standard } \\
\text { deviation }\end{array}$ & Level \\
\hline 1 & Teaching methods do not match the level of students & 2.24 & .725 & Medium \\
\hline 2 & The use of the Arabic language by the teacher & 2.14 & .784 & Medium \\
\hline 3 & Lack of use of educational tools in the explanation & 2.12 & .743 & Medium \\
\hline 4 & $\begin{array}{l}\text { Giving priority to the theoretical side over the practical side in } \\
\text { teaching methods }\end{array}$ & 2.12 & .741 & Medium \\
\hline 5 & $\begin{array}{l}\text { Students are not able to access resources for self-learning of } \\
\text { the language }\end{array}$ & 2.11 & .770 & Medium \\
\hline 6 & Directing teaching towards answering specific exam questions & 2.09 & .753 & Medium \\
\hline 7 & Focus on grammar without training in using them & 2.07 & .778 & Medium \\
\hline 8 & $\begin{array}{l}\text { Weakness in providing feedback to students and their parents } \\
\text { about their evaluation results }\end{array}$ & 2.07 & .747 & Medium \\
\hline & Total & 2.12 & .488 & Medium \\
\hline
\end{tabular}

It is evident from Table 4, that the overall degree of assessment of the causes of learning difficulties in the field of teaching methods was generally medium, and that all of its statements were also medium. The statement, "The use of the Arabic language by the teacher" came in the first place, while the two statements, "Weakness in providing feedback to students and their parents about their evaluation results", ranked last.

\section{The third field: assessment methods}

Table 5 shows the mean scores and standard deviations of the causes of learning difficulties among primary school students in English language, and the overall degree of appreciation for the assessment methods field and its sub-statements. 
Table 5. The mean scores and standard deviations of the statements of the assessment methods field arranged in descending order according to the mean scores

\begin{tabular}{clccc}
\hline \multirow{2}{*}{ Rank } & \multicolumn{1}{c}{ Statement } & $\begin{array}{c}\text { Mean } \\
\text { score }\end{array}$ & $\begin{array}{c}\text { Standard } \\
\text { deviation }\end{array}$ & Level \\
\hline 1 & The assessment process is not comprehensive & 2.24 & .784 & Medium \\
2 & Not following up on homework & 2.22 & .739 & Medium \\
3 & assessment discontinuity & 2.21 & .762 & Medium \\
4 & Poor evaluation of students' listening skills & 2.20 & .751 & Medium \\
5 & Not taking into account individual differences between & 2.17 & .752 & Medium \\
& students during teaching & 2.12 & .725 & Medium \\
\hline & Focus on lower levels of educational goals & 2.19 & .521 & Medium \\
\hline
\end{tabular}

It is clear from in Table 5, that the overall degree of assessment of the causes of learning difficulties in the assessment methods field was medium, and all its statements were also medium. The statement, "The assessment process is not comprehensive" came in the first place, while the statement, " Focus on lower levels of educational goals" came in the last place.

\section{The fourth field: school and home environment}

Table 6 shows the mean scores and standard deviations of the causes of students' learning difficulties in English in the primary stage and the total degree of appreciation for the school and home environment field and its sub-statements.

Table 6. The mean scores and standard deviations of the statements of the school and home environment field arranged in descending order according to the mean scores

\begin{tabular}{|c|c|c|c|c|}
\hline Rank & Statement & $\begin{array}{l}\text { Mean } \\
\text { score }\end{array}$ & $\begin{array}{l}\text { Standard } \\
\text { deviation }\end{array}$ & Level \\
\hline 1 & Parents' preoccupation with following up on the student & 2.25 & .748 & Medium \\
\hline 2 & Unavailability of a suitable place for students to study & 2.24 & .780 & Medium \\
\hline 3 & Students are preoccupied with work other than studying & 2.19 & .771 & Medium \\
\hline 4 & High numerical density in the classes & 2.17 & .781 & Medium \\
\hline 6 & The use of physical punishment with students & 2.16 & .774 & Medium \\
\hline 7 & $\begin{array}{l}\text { The presence of students in a culturally poor environment in } \\
\text { terms of language use }\end{array}$ & 2.15 & .796 & Medium \\
\hline 7 & $\begin{array}{l}\text { Disruption of the social relationship between teachers and } \\
\text { students }\end{array}$ & 2.15 & .735 & Medium \\
\hline 9 & $\begin{array}{l}\text { Some teachers follow teaching methods that are higher than } \\
\text { the level of students }\end{array}$ & 2.13 & .785 & Medium \\
\hline \multirow[t]{2}{*}{10} & $\begin{array}{l}\text { Lack of incentives to encourage students to continue } \\
\text { studying }\end{array}$ & 2.12 & .784 & Medium \\
\hline & Total & 1.90 & .820 & Medium \\
\hline
\end{tabular}

It is clear from the results in Table 6, that the overall degree of estimation for the causes of language learning difficulties was medium, and that all of its statements were also medium. The statement, "Parents' preoccupation with following up on the student" came in the first place, while the statement, " Lack of incentives to encourage students to continue studying" ranked last.

The results showed that all students' assessments of the causes of students' learning difficulties in English language were medium. The medium values of the field of curriculum mean that there is weakness that students face due to the curriculum. The researcher attributes the reason for this to the curriculum's focus on the grammatical aspect of the language and not the applied aspect of the language. In addition, the curriculum is not related to the reality of the students, and does not provide the students with real and realistic educational situations that enable them to deal with the problems of the reality in which they live.

The results also showed that all students' assessments of the reasons for weakness in English were medium in the teaching methods field, which means that there are weaknesses faced by students with regard to teaching methods. The researcher attributes this to the lack of mastery of English language teachers of the material, especially with regard to teaching tools. The teacher does not activate the teaching tools in the classroom because he does not feel their importance. He frequently uses the Arabic language on the grounds that English is a language other than that spoken by students. And because he believes that if he speaks in English throughout the class, his students will not understand what they are told in the class.

The results also showed that all students' ratings in the field of assessment methods received high ratings. 
Theis value mean that there is a weakness that students face in their learning of English language due to assessment methods. The researcher attributes the reason to teachers neglecting students' homework and not considering them as part of the assessment process. teachers do not correct students often and show them the right answers.

The results also showed that all students' ratings for the reasons for weakness in the home and school environment were medium. The medium values of this field mean that there is a weakness that students face in English language, which is due to the home and school environment. This indicates that students do not pay much attention to their studies, as they occupy most of their time in work other than studying, in addition to the family's lack of interest in students.

\section{ACKNOWLEDGMENTS}

The authors extend their appreciation to the Deanship of Scientific Research at King Khalid University for funding this work through Small Research Groups under grant number (RGP.1/40/42).

\section{RECOMMENDATION}

One of the most prominent recommendations of this study is to focus on the need to diversify in teaching methods, reduce the teaching burden for teachers from lessons, and open channels of communication between family and school to follow up on students' affairs. It is recommended to identify problems in the process of learning English and increasing the awareness of students and their families about the importance of learning English. In addition, encouraging schools to establish a special English language laboratory equipped with the latest equipment to enable students to listen to the language better and with sound pronunciation, and to encourage teachers to develop remedial plans to improve the achievement level of students.

\section{REFERENCES}

Abu Salah, A. Y. \& Al-Hadidi, M. A. (2017). Difficulties of Learning Writing in English Language Faced by (4 - 6) Primary Grades Students from the Point of View of their Teachers in the Capital Amman. Middle East University, Amman. Retrieved from http://search.mandumah.com/Record/903018

Al-Arifi, R. S. (2020). Difficulties facing teaching English Language at the primary level from the point of view of teachers and the proposed solutions for them in Al-Quwaiyah Governorate. Reading and Knowledge Journal, 20(2), 117-148.

Alimat, A., Al-Sa ida, M. \& Al-Ziyadat, E. (2013). The reasons for the low level of academic achievement in English language curriculum for secondary school students in public schools in Salt from the point of view of teachers and the proposed solutions to improve the achievement level. Faculty of education journal.

Almousah, M. H. A. (2020). The obstacles to teaching English for the secondary stage in the Education Directorate in the Aqaba Governorate from the viewpoint of the subject teachers.

Al-Mutairi, M. (2009). Teaching problems of English language teacher in the primary stage in Al-Mahd Governorate. Unpublished Master thesis. Umm Al-Qura University, Medina, Saudi Arabia.

Al-Sane, O. J. (2009). Reasons for the low level of primary school pupils in English language from the point of view of their teachers in the State of Kuwait. Reading and Knowledge Magazine - Egypt, p. 14, 41-91.

Al-Zoubi, R. (2013). Students' preoccupation with learning English and its relationship to students' relationship with English language teachers and their attitudes towards learning it. The Jordanian Journal of Educational Sciences, (2),221-241.

Badawi, A. M. M., \& Hamid, F. M. H. (2020). Analyzing the Difficulties Encountered by Basic Schools in some English Consonant Sounds and Clusters: Teachers' Perspectives.

Khasawneh, M. A. (2019). Using Social Media Networks by Learning Disabilities Teachers. International Journal of Educational Research Review, 4, 766-780.

Khalaf, M. K. \& Fadel, R. A. (2020). Analysis of Written Discourse Errors Committed by Iraqi EFL Learners. Studies - Humanities and Social Sciences: Jordan University - Deanship of Scientific Research, 47, Supplement, 521-532.

Massadeh, E. M. (2018). Educational problems facing basic stage students in learning English (Doctoral dissertation). 
Minshar, M. A. (2020). The effect of using educational games on third-grade students' achievement of English vocabulary in the Hebron governorate. Psychological and educational studies journal, 13(3), 309319.

Nuruzzaman, M., Islam, A. S., \& Shuchi, I. J. (2018). An analysis of errors committed by Saudi non-English major students in the English paragraph writing: A study of comparisons. Advances in language and literary studies, 9(1), 31-39.

Saadeh, J. A \& Damour, S. H. (2017). Problems of teaching English for first year secondary students in the educational district of Karak from the point of view of teachers.

Turki, H. (2019). The reasons for the low achievement of students in learning English from the point of view of teachers. (Doctoral dissertation).

Yousif, A. A., \& Abdalla, A. Y. (2020). Investigating English Prepositions Problems Encountered by Undergraduate Sudanese Students in Writing. 